\title{
Validation of the Cosmetic Procedure Screening (COPS) Questionnaire in the Greek language
}

\author{
Athina Kallianta ${ }^{1 凶}$, Flora Bacopoulou ${ }^{2}$, Dimitrios Vlachakis ${ }^{2,3,4}$, loulia Kokka ${ }^{1}$, George P. Chrousos ${ }^{2}$, Christina \\ Darviri $^{1}$
} 1Postgraduate Course of Science of Stress and Health Promotion, School of Medicine, National and Kapodistrian University of
Athens, Athens, Greece

2University Research Institute of Maternal and Child Health \& Precision Medicine and UNESCO Chair on Adolescent Health Care, National and Kapodistrian University of Athens, Aghia Sophia Children's Hospital, Athens, Greece

${ }^{3}$ Laboratory of Genetics, Department of Biotechnology, School of Applied Biology and Biotechnology, Agricultural University of Athens, Athens, Greece

${ }^{4}$ Lab of Molecular Endocrinology, Center of Clinical, Experimental Surgery and Translational Research, Biomedical Research Foundation of the Academy of Athens, Athens, Greece

Competing interests: AK none; FB none; DV none; IK none; GPC none; CD none

\section{Abstract}

Practitioners in cosmetic and aesthetic treatment practices are likely to unknowingly work with patients with Body Dysmorphic Disorder (BDD). Screening questionnaires to identify the disorder in Greece are lacking. The purpose of this study was to validate a Greek version of the Cosmetic Procedure Screening (COPS) questionnaire, a self-report measure of how the respondents feel about their appearance, before an aesthetic intervention. The COPS was translated into Greek and was completed by 216 adult females from several areas of Attica (four private beauty centers, three dermatology clinics, five plastic surgery clinics, and Thriasio General Hospital of Elefsina) who pursued a cosmetic procedure. Participants also completed the Perceived Stress Scale (PSS-14). The Greek version of the COPS questionnaire demonstrated high internal consistency (Cronbach's $\alpha$ of 0.856 ) with corrected item's total range 0.468 to 0.687 . Two of the factors explained $58.98 \%$ of total variance. Twenty $(9.26 \%)$ women had a possible diagnosis of BDD ( $80 \%$ were unmarried, $95 \%$ had no children, $80 \%$ had university education). An increase in perceived stress levels was associated with an increase in the likelihood of being diagnosed with BDD (Pearson's $r=0.726$ ). The Greek version of the COPS questionnaire is a valid instrument that can be used by professionals to screen adult women for BDD.

\section{Introduction}

Body Dysmorphic Disorder (BDD) is a psychiatric condition which is not well-known, nor has been investigated for long as other established psychiatric disorders. However, before the disorder's first inclusion in the 3rd edition of the Diagnostic and Statistical Manual of Mental Disorders (DSM-III), case reports of individuals with characteristics of the disorder did appear in the cosmetic surgery literature (APA, 1980). Edgerton et al. described patients who were preoccupied with "minor deformities" as well as others who could not be satisfied with the cosmetic surgery result and returned for additional procedures (Edgerton et al., 1960; Knorr et al., 1967). Similar findings were reported in the field of dermatology research (Cotterill et al., 1981). Thus, it appears that clinicians involved with cosmetic surgical treatments were familiar with some of the characteristics of the condition before its formal recognition as a diagnostic entity in the psychiatry literature.

The incidence of BDD increases among patients who seek aesthetic medical treatments. Studies that have examined BDD regardless of the type of treatment, consistently suggest that $5 \%$ to $15 \%$ of patients have some form of the disorder (Sarwer et al., 1998; Aouizerate et al., 2003; Vulink et al., 2006), while other authors that conducted clinical interviews of patients, report higher rates, up to approximately $20 \%$ of patients (Altamura et al., 2001; Vargel et al., 2001; Bellino et al., 2006). Others have investigated the presence of BDD in people who sought dermatological treatment. Among these studies, the rates of $\mathrm{BDD}$ were quite similar to those in patients

\section{Article history \\ Received: 27 November 2020 \\ Accepted: 24 December 2020 \\ Published: 23 August 2021}

(c) 2021 Kallianta et al:; the authors have retained copyright and granted the Journal right of first publication; the work has been simultaneously released under a Creative Commons Attribution Licence, which allows others to share the work, while acknowledging the original authorship and initial publication in this Journal. The full licence notice is available at http://journal.embnet.org. 
interested in purely aesthetic treatments, ranging from 8.5\% to 15\% (Uzun et al., 2003; Bowe et al., 2007).

According to the systematic review of Veale et al. who aimed to determine the prevalence of BDD in different settings and the differences between the sexes, the total prevalence in the category of aesthetic dermatology was $9.2 \%$ with women $(14.7 \%)$ outnumbering men (7.1\%), total prevalence in the category of general cosmetic surgery was $13.2 \%$ with men $(15.3 \%)$ outnumbering women $(10.9 \%)$, and total prevalence in the category of acne treatment clinics was $11.1 \%$ without differences between the two sexes (Veale et al., 2016). A meta-analysis conducted one year later by Ribeiro on the prevalence of BDD among plastic surgery and dermatology patients, came to add to the existing literature that $15.04 \%$ of plastic surgery patients with a mean age $( \pm$ SD) of $34.54( \pm 12.41)$ years had a BDD, while among the dermatological patients, $12.65 \%$ had the disorder with an average age $( \pm$ SD) of $27.79( \pm$ 9.03) years. The majority of BDD cases in both categories were women (Ribeiro, 2017). In a more recent review by Sarwer, it was typically reported that many individuals underwent cosmetic interventions experiencing strong dissatisfaction with their image, a clinical picture similar to that of BDD and it is speculated that $5-15 \%$ of people seeking cosmetic treatment suffer from BDD (Sarwer, 2019). According to the literature so far, there have been increased rates of BDD worldwide among the facilities that deal with aesthetics (Veale et al., 2016).

Body dysmorphic disorder is considered a "silent" psychiatric disorder. Patients are reluctant to discuss their concerns with medical professionals, fearing that their stress originating from their appearance will be disregarded. Therefore, they seek comfort without ever being properly diagnosed (Lai et al., 2010). Their unrealistic expectations maintain their dissatisfaction even after a successful operation, and thus intensify the feeling of discomfort and stress that accompanies them (Castle et al., 2002). A meta-analysis that compared the quality of life of individuals without BDD who underwent cosmetic surgery, pre- and post-operatively, showed that their quality of life at a psychological and practical level had greatly improved post-operatively (Dreher et al., 2016; Wang et al., 2016). However, this does not seem to be the case with BDD patients. Most of them do not see real improvement after a successful aesthetic intervention, which leaves them unhappy and may aggravate the symptoms of the disorder. Therefore, BDD is considered a contraindication for cosmetic medicine treatments (Phillips, 2009; Wang et al., 2016; Higgins et al., 2017; Sarwer, 2019).

An early diagnosis of BDD, facilitated by appropriate diagnostic tools, could play a decisive role in the professional-patient relationship, and would allow the health scientist (dermatologist, plastic surgeon) to adequately predict the needs of the particular patient (Jakubietz et al., 2007; Kyle, 2012).

Data are scarce regarding the prevalence of BDD in such patients in Greece and there is also lack of validated screening instruments. The Cosmetic Procedure Screening (COPS) questionnaire is a self-report measure based on the DSM-IV criteria (APA, 1994) for $\mathrm{BDD}$, that aims to gather information about how the respondent feels about his/her appearance, before an aesthetic intervention. The aim of the present study was to translate and validate the COPS questionnaire in the Greek language.

\section{Materials, Methodologies and Techniques}

\section{Translation procedure}

The research team was authorized by Dr. David Veale to validate the Greek version of the COPS questionnaire. A bilingual translation was performed in two directions (forward translation, backward translation). At first the COPS questionnaire was translated from the English into the Greek language by two different Greek native speakers with very good knowledge of English (forward translation). Comparison of the two translations resulted in the 1st version of the questionnaire in Greek, which was re-translated into English by a professional Greek translator (backward translation). The result of this translation was compared with the original questionnaire to record any differences and comments, which were then incorporated into the already existing Greek translation (1st version). As a result of this comparison and the corrections that were needed, a 2nd version of the Greek questionnaire emerged which was applied to a small sample of volunteers to check the understanding and the proper wording of the questions to correct any possible mistakes or omissions. Observations and comments from this test sample were recorded and then incorporated in the 2nd version of the Greek questionnaire. With the completion of the above procedure, the final Greek version of the COPS questionnaire emerged, which was then subjected to a final reliability and validity test.

\section{Participants}

The study sample was recruited from several areas of Attica, 4 private beauty centers, 3 dermatology clinics, 5 plastic surgery clinics and the Thriasio General Hospital of Elefsina. Females seeking a cosmetic procedure were included in the study if they were 18 years of age or older and were able to read and write in the Greek language. The study was performed in accordance with the ethical standards of the 1964 Declaration of Helsinki and its later amendments. The study protocol was approved by the Ethics committee of the Thriasio General Hospital (protocol no 405/03-12-2019). Women were informed about the purpose of the study and signed a consent form prior to study entry. All participants completed the Greek version of the COPS questionnaire, the Perceived Stress Scale, as well as a structured questionnaire for socio-demographic characteristics. 


\section{Measures}

Socio-demographic data: A properly structured questionnaire was used to gather information about the demographic characteristics of the respondents. These included age, location of residence, educational level, employment, marital status, and whether they had children or not.

Cosmetic Procedure Screening (COPS) questionnaire: The COPS questionnaire comprises 10 items. Only items 2 to 10 are scored on a 9-point scale from 0 (least impaired) to 8 (most impaired). The first item defines the features that the person finds unattractive in his/her appearance and is not part of the total score. The remaining 9 items of the COPS questionnaire investigate the extent to which the features reported in question 1 concern the individual and how much stress is caused (distress) by them or make him/her dysfunctional in important areas of life, according to the diagnostic criteria of the BDD.

The questionnaire examines the following: $A$. the individual's excessive concern for a perceived or existing defect in his/her appearance (questions Q 2,3,4,6), and B. the clinically significant discomfort or dysfunction in social, professional or other important areas of life caused by this concern (questions Q 5,7,8,9,10). The score is achieved by summing Q 2-10. Items 2,3 and 5 are reversed. The total score ranges from 0 to 72 with a higher score reflecting greater impairment and symptoms of BDD. Individuals who score 40 or more are likely to have a diagnosis of BDD (Veale et al., 2012).

Perceived Stress Scale (PSS-14): The Greek version of the PSS-14 was used (Andreou et al., 2011). This is a 14-item self-report instrument that measures the degree to which situations in a person's life are reported as stressful or not. The frequency of emotions and thoughts during the previous month is rated on a 5 -point Likert scale (from $0=$ never to 4 = very often). There are seven positive and seven negative elements, and the total score is calculated by summing the score of each element, after all the positive elements have been reversed (minimum total score $=0$, maximum total score =56). Higher scores indicate a higher level of perceived stress of the person during the last month. PSS-14 was found to have satisfactory internal consistency (Cronbach's alpha $=0.85)$ (Cohen et al., 1983).

\section{Statistical analysis}

Descriptive analyses were used to calculate frequencies (\%), means (min-max) and standard deviations (SD). The Kaiser-Meyer-Olkin (KMO) statistic and Barlett's Sphericity Test were used to examine sample's adequacy. Exploratory Factor Analysis was performed to identify items' factors. Cronbach's alpha values were calculated to assess internal consistency of the questionnaire. Total scores of the instrument were calculated and the association with demographic characteristics of the sample was explored with One-way ANOVA test.

Table 1. Descriptive characteristics of the study sample.

\begin{tabular}{|c|c|c|c|c|c|c|}
\hline & & $\begin{array}{l}\text { Participants } \\
\qquad N=216\end{array}$ & COPS $>=40$ & $\begin{array}{l}\% \text { BDD } \\
\text { cases in } \\
\text { category }\end{array}$ & $\begin{array}{c}\% \text { BDD } \\
\text { cases out of } \\
\text { total BDD } \\
\text { cases }\end{array}$ & $\begin{array}{c}\% \text { BDD } \\
\text { cases out of } \\
\text { total cases }\end{array}$ \\
\hline \multirow[t]{3}{*}{ Age (years) } & $18-30$ & 67 & 8 & $12 \%$ & $40 \%$ & $4 \%$ \\
\hline & $31-45$ & 107 & 8 & $7 \%$ & $40 \%$ & $4 \%$ \\
\hline & $46+$ & 42 & 4 & $10 \%$ & $20 \%$ & $2 \%$ \\
\hline \multirow[t]{4}{*}{ Educational level } & Primary Education & 3 & 0 & $0 \%$ & $0 \%$ & $0 \%$ \\
\hline & Secondary Education & 28 & 2 & $7 \%$ & $10 \%$ & $1 \%$ \\
\hline & Higher Education & 131 & 16 & $12 \%$ & $80 \%$ & $7 \%$ \\
\hline & Postgraduate Education & 54 & 2 & $4 \%$ & $10 \%$ & $1 \%$ \\
\hline \multirow[t]{6}{*}{ Employment status } & Freelancer & 45 & 1 & $2 \%$ & $5 \%$ & $0 \%$ \\
\hline & State Employee & 35 & 5 & $14 \%$ & $25 \%$ & $2 \%$ \\
\hline & Private Employee & 99 & 12 & $12 \%$ & $60 \%$ & $6 \%$ \\
\hline & University Student & 21 & 2 & $10 \%$ & $10 \%$ & $1 \%$ \\
\hline & Retired & 3 & 0 & $0 \%$ & $0 \%$ & $0 \%$ \\
\hline & Unemployed & 13 & 0 & $0 \%$ & $0 \%$ & $0 \%$ \\
\hline \multirow[t]{4}{*}{ Marital status } & Married & 82 & 3 & $4 \%$ & $15 \%$ & $1 \%$ \\
\hline & In Relationship & 52 & 10 & $19 \%$ & $50 \%$ & $5 \%$ \\
\hline & Single & 60 & 6 & $10 \%$ & $30 \%$ & $3 \%$ \\
\hline & Separated/ Divorced & 22 & 1 & $5 \%$ & $5 \%$ & $0 \%$ \\
\hline \multirow[t]{2}{*}{ Children } & Yes & 58 & 1 & $2 \%$ & $5 \%$ & $0 \%$ \\
\hline & No & 158 & 19 & $12 \%$ & $95 \%$ & $9 \%$ \\
\hline
\end{tabular}


Table 2. Rotated factor loadings of PCA for the 9 items of COPS questionnaire $(\mathrm{N}=216)$.

\begin{tabular}{lll} 
Items & Initial & Extraction \\
\hline Q02 & 1.000 & .353 \\
\hline Q03 & 1.000 & .713 \\
\hline Q04 & 1.000 & .680 \\
\hline Q05 & 1.000 & .484 \\
\hline Q06 & 1.000 & .726 \\
\hline Q07 & 1.000 & .601 \\
\hline Q08 & 1.000 & .605 \\
\hline Q09 & 1.000 & .645 \\
\hline Q10 & 1.000 & .501 \\
\hline \% of Variance & & 58.98 \\
\hline Cronbach's $\alpha$ & & 0.88
\end{tabular}

PCA: Principal Component Analysis, COPS: Cosmetic Procedure Screening, Q: question

Statistical analyses were performed using IBM SPSS version 24.0.

\section{Results}

The questionnaire was completed by 216 adult women who pursued a cosmetic procedure. According to the scale of the COPS questionnaire, 9.26\% $(\mathrm{N}=20)$ of participating women had a possible diagnosis of BDD. The socio-demographic characteristics of the study sample are presented in Table 1.

The KMO coefficient and Barlett's Sphericity test ( $x 2)$ were first calculated, to examine the adequacy and suitability of the data collected. KMO fit coefficient was 0.88 , which verified the sample's adequacy for analysis and $X^{2}$ was $689.586, \mathrm{P}<.001$, which indicated that correlations between items were sufficiently large enough to perform Exploratory Factor Analysis (EFA). EFA was performed with Principal Component Analysis (PCA). With regards to the internal consistency of the questionnaire Cronbach's $\alpha$ was 0.856 , with corrected item total range 0.468 to 0.687 which indicates a high internal consistency. Table 2 presents the results of the PCA. Two of the factors had an eigenvalue greater than Kaiser's criterion of 1 and explained $58.98 \%$ of the total variance.

Reliability of the COPS questionnaire was explored by internal consistency (Cronbach's $\alpha$ ). The average coefficient alpha value was 0.88 , quite similar to that observed in the original study. Table 3 presents the means, standard deviations, and Cronbach's $\alpha$ values if items of the scale were deleted.

Associations between COPS scores and the sociodemographic characteristics of the sample were explored and presented in Table 4. Statistically significant correlations $(\mathrm{P}<.05)$ of $\mathrm{BDD}$ were observed with the educational level, the presence or absence of children and the marital status of the participants, while non-
Table 3. Descriptive statistics for the COPS questionnaire.

\begin{tabular}{|c|c|c|c|}
\hline $\begin{array}{l}\text { Item } \\
\text { Statistics }\end{array}$ & Mean & $\begin{array}{c}\text { Std. } \\
\text { Deviation }\end{array}$ & $\begin{array}{c}\text { Cronbach's } \\
\alpha \text { if item } \\
\text { deleted }\end{array}$ \\
\hline Q02 & 2.37 & 1.485 & .850 \\
\hline Q03 & 3.10 & 1.947 & .845 \\
\hline Q04 & 2.68 & 2.017 & .829 \\
\hline Q05 & 1.06 & 1.707 & .846 \\
\hline Q06 & 3.23 & 1.937 & .833 \\
\hline Q07 & 1.93 & 2.140 & .830 \\
\hline Q08 & .51 & 1.181 & .845 \\
\hline Q09 & 1.60 & 1.977 & .837 \\
\hline Q10 & 2.56 & 2.059 & .845 \\
\hline
\end{tabular}

COPS: Cosmetic Procedure Screening, Q: question

significant correlations $(\mathrm{P}>.05)$ were found between the BDD scores and type of employment and age.

A regression analysis was applied to examine the causal relationship between the study quantitative variables (COPS and PSS-14), as shown in Table 5.

According to the regression data there is a statistically significant correlation $(\mathrm{P}<.05)$ between COPS and PSS-14. More specifically, an increase in perceived stress levels was associated with an increase in the likelihood of being diagnosed with BDD (Pearson's $r=0.726)$.

\section{Discussion}

The aim of this study was to validate the COPS questionnaire in the Greek language. Body dysmorphic disorder is characterized by preoccupation with thoughts and behaviours regarding appearance concerns. It is a disabling mental health condition where a perceived physical defect impairs everyday life functioning (Bowyer et al., 2016; Singh and Veale, 2019). BDD is commonly under-diagnosed or mis-diagnosed by physicians and practitioners in cosmetic procedures (Bowyer et al., 2016). Moreover, a large proportion of BDD patients presenting to non-psychiatry-related specialists may not identify themselves as suffering from a mental disorder (Singh and Veale, 2019). Many BDD patients seek dermatological, surgical, or cosmetic interventions trying to correct their perceived defect, and instead of the psychiatric help that they actually need, they receive treatments which often lead to lack of satisfaction with the performed procedure (Bowyer et al., 2016). Among other questionnaires assessing BDD symptoms, the COPS questionnaire is the only one created for patients undergoing cosmetic procedures (Phillips et al., 1997; Phillips, 2005; Phillips, 2009; Phillips, 2017). Compared to the original version, the translated Greek version of the COPS questionnaire 
Table 4. One-way ANOVA test with the results of the F-test.

\begin{tabular}{|c|c|c|c|c|c|c|}
\hline & & $\begin{array}{l}\text { Sum of } \\
\text { Squares }\end{array}$ & Df & Mean Square & $\mathbf{F}$ & Sig. \\
\hline \multirow[t]{3}{*}{ Age } & Between Groups & 324.024 & 2 & 162.012 & 1.260 & .286 \\
\hline & Within Groups & 27381.809 & 213 & 128.553 & & \\
\hline & Total & 27705.833 & 215 & & & \\
\hline \multirow[t]{3}{*}{ Source } & Between Groups & 1028.404 & 3 & 342.801 & 2.724 & .045 \\
\hline & Within Groups & 26677.429 & 212 & 125.837 & & \\
\hline & Total & 27705.833 & 215 & & & \\
\hline \multirow[t]{3}{*}{ Educational Level } & Between Groups & 1198.979 & 2 & 599.490 & 4.817 & .009 \\
\hline & Within Groups & 26506.854 & 213 & 124.445 & & \\
\hline & Total & 27705.833 & 215 & & & \\
\hline \multirow[t]{3}{*}{ Marital Status } & Between Groups & 1425.275 & 3 & 475.092 & 3.832 & .011 \\
\hline & Within Groups & 26280.558 & 212 & 123.965 & & \\
\hline & Total & 27705.833 & 215 & & & \\
\hline \multirow[t]{3}{*}{ Kids } & Between Groups & 820.812 & 1 & 820.812 & 6.534 & .011 \\
\hline & Within Groups & 26885.021 & 214 & 125.631 & & \\
\hline & Total & 27705.833 & 215 & & & \\
\hline \multirow[t]{3}{*}{ Employment Status } & Between Groups & 375.662 & 4 & 93.916 & 0.725 & .576 \\
\hline & Within Groups & 27330.171 & 211 & 129.527 & & \\
\hline & Total & 27705.833 & 215 & & & \\
\hline
\end{tabular}

showed a lower, however sufficient, value of Cronbach $\alpha$ coefficient ( 0.91 vs. 0.88 , respectively). Nonetheless, the results of convergent validity revealed remarkably similar results to those obtained in the original paper, showing a significant relationship with perceived psychological distress. The Greek validation showed that among the 216 participants, 20 cases had a possible diagnosis of BDD, which corresponds to a percentage of 9.26\% that coincides with the existing literature (Veale et $a l ., 2016)$. The results of this study are also in line with previous literature with regards to the importance of age and marital status. The majority of BDD cases were not in a committed relationship ( $80 \%$ were unmarried and 95\% had no children) (Hartmann and Buhlmann, 2017). Interestingly, age did not seem to affect the likelihood of diagnosis as there was no correlation between possible diagnosis of BDD and age of the respondents (Phillips, 2020). The educational level was found to have a statistically significant correlation with the disorder with $80 \%$ of BDD possible cases reporting to have university education.

Table 5. Linear Regression.

\begin{tabular}{l|c|c|c|c} 
& B & $\begin{array}{c}\text { Std. } \\
\text { Error }\end{array}$ & t & Sig. \\
\hline Constant & -5.0276 & 1.6447 & -3.0569 & .003 \\
\hline PSS-14 & 0.9418 & 0.0609 & 15.4577 & .000 \\
\hline
\end{tabular}

Pearson's $\mathbf{r}=$

0.726

PSS-14: Perceived Stress Scale
Screening for BDD is essential in cosmetic surgery practice. To our knowledge, the Greek version of the COPS questionnaire is the first instrument for BDD screening in the Greek language. It is a valid instrument that can be used in cosmetic procedure settings to screen adult women for BDD. It can also be used as an outcome measure after treatment to determine if there is any improvement or persistence in the symptoms of BDD following a cosmetic procedure.

\section{Key Points}

- Screening questionnaires for Body Dysmorphic Disorder (BDD) in Greece are lacking.

- The incidence of BDD increases in patients seeking aesthetic/ cosmetic treatments .

- The Cosmetic Procedure Screening (COPS) questionnaire is a screening tool for BBD.

- The Greek version of the COPS questionnaire demonstrated high internal consistency.

- The Greek version of COPS can be used for screening adult women for BDD in Greece.

\section{References}

1. Andreou E, Alexopoulos EC, Lionis C, Varvogli L, Gnardellis C et al. (2011) Perceived stress scale: Reliability and validity study in greece. International Journal of Environmental Research and Public Health 8(8), 3287-3298. http://dx.doi.org/10.3390/. ijerph8083287.

2. Altamura C, Paluello MM, Mundo E, Medda S, Mannu P (2001) Clinical and subclinical body dysmorphic disorder. Eur Arch Psychiatry Clin Neurosci 252(3), 105-108. http://dx.doi. org/10.1007/s004060170042 
3. American Psychiatric Association (1980) Diagnostic and statistical manual of mental disorders (3th ed.). Washington, DC American Psychiatric Association.

4. American Psychological Association (1994) Diagnostic and statistical manual of mental disorders (4th ed.). Washington, DC American Psychiatric Association.

5. Aouizerate B, Pujol H, Grabot D, Faytout M, Suire K et al. (2003) Body dysmorphic disorder in a sample of cosmetic surgery applicants. Eur Psychiatry 18(7), 365-368. http://dx.doi org/10.1007/s004060170042

6. Bellino S, Zizza M, Paradiso E, Rivarossa A, Fulcheri M et al. (2006) Dysmorphic concern symptoms and personal-ity disorders: a clinical investigation in patients seeking cosmetic surgery. Psychiatry Res 144, 73-78. http://dx.doi.org/10.1016/j. psychres.2005.06.010

7. Bowe WP, Leyden JJ, Crerand CE, Sarwer DB, Margolis DJ (2007) Body dysmorphic disorder symptoms among patients with acne vulgaris. J Am Acad Dermatol 57, 222-230. http://dx.doi. org/10.1016/j.jaad.2007.03.030

8. Bowyer L, Krebs G, Mataix-Cols D, Veale D, Monzani B (2016) A critical review of cosmetic treatment outcomes in body dysmorphic disorder. Body Image 19, 1-8. http://dx.doi. org/10.1016/j.bodyim.2016.07.001

9. Castle DJ, Honigman RJ, Phillips KA (2002) Does cosmetic surgery improve psychosocial wellbeing? The Medical Journal of Australia 176(12), 601-604. http://dx.doi.org/10.5694/j.1326-5377.2002. tb04593.x

10. Cohen S, Kamarck T, Mermelstein R (1983) A Global Measure of Perceived Stress. Journal of Health and Social Behavior 24, 385396. http://dx.doi.org/10.2307/2136404

11. Cotterill J (1981) Dermatological non-disease: a common and potentiallyfataldisturbance of cutaneousbodyimage. BrJDermatol 104, 611-619. http://dx.doi.org/10.1111/j.1365-2133.1981. tb00746.x

12. Dreher R, Blaya C, Tenório JL, Saltz R, Ely PB et al. (2016) Quality of Life and Aesthetic Plastic Surgery: A Systematic Review and Meta-analysis. Plast Reconstr Surg Glob Open 4(9), e862. http:// dx.doi.org/10.1097/GOX.00000000000000833

13. Edgerton MT, Jacobson WE, Meyer E (1960) Surgical-psychiatric study of patients seeking plastic (cosmetic) surgery: ninety-eight consecutive patients with minimal deformity. Br J Plast Surg 13 136-145. http://dx.doi.org/10.1016/s0007-1226(60)80029-x

14. Hartmann AS and Buhlmann U (2017) Prevalence and underrecognition of body dysmorphic disorder. In K. A. Phillips (Ed.), Body dysmorphic disorder: Advances in research and clinical practice. Oxford University Press p.49-60. http://dx.doi. org $/ 10.1093 / \mathrm{med} / 9780190254131.003 .0005$

15. Higgins S and Wysong A (2017) Cosmetic Surgery and Body Dysmorphic Disorder - An Update. Int J Womens Dermatol 4(1), 43-48. http://dx.doi.org/10.1016/j.ijwd.2017.09.007

16. Jakubietz M, Jakubietz RJ, Kloss DF, Gruenert JJ (2007) Body dysmorphic disorder: diagnosis and approach. Plastic and Reconstructive Surgery 119(6), 1924-1930. http://dx.doi. org/10.1097/01.prs.0000259205.01300.8b

17. Knorr NJ, Edgerton MT, Hoopes JE (1967) The "insatiable" cosmetic surgery patient. Plast Reconstr Surg 40(3), 285-289.
18. Kyle A (2012) Body dysmorphia and plastic surgery. Plastic Surgical Nursing 32(3), 96-98. http://dx.doi.org/10.1097/ PSN.0b013e31826a9d90

19. Lai CS, Lee SS, Yeh YC, Chen CS (2010) Body dysmorphic disorder in patients with cosmetic surgery. The Kaohsiung Journal of Medical Sciences 26(9), 478-482. http://dx.doi.org/10.1016/ S1607-551X(10)70075-9

20. Phillips KA, Hollander E, Rasmussen SA, Aronowitz BR, DeCaria Cet al. (1997) A severity rating scale for body dysmorphic disorder: development, reliability, and validity of a modified version of the Yale-Brown Obsessive Compulsive Scale. Psychopharmacol Bull 33, 17-22.

21. Phillips KA (2005) The broken mirror: Understanding and treating body dysmorphic disorder (Rev. \& exp ed.). Oxford University Press.

22. Phillips KA (2009) Understanding body dysmorphic disorder: An essential guide. Oxford University Press.

23. Phillips KA (2017) Body Dysmorphic Disorder: Advances in Reasearch and Clinical Practice. Oxford University Press.

24. Phillips KA (2020) Who gets BDD? https://bdd.iocdf.org/aboutbdd/who-gets-bdd (accessed 19 September 2020).

25. Ribeiro RVE (2017) Prevalence of Body Dysmorphic Disorder in Plastic Surgery and Dermatology Patients: A Systematic Review with Meta-Analysis. Aesthetic Plastic Surgery 41(4), 964-970. http://dx.doi.org/10.1007/s00266-017-0869-0

26. Sarwer DB (2019) Body image, cosmetic surgery, and minimally invasive treatments. Body Image 31 302-308. http://dx.doi. org/10.1016/j.bodyim.2019.01.009

27. Singh AR and Veale D (2019) Understanding and treating body Dysmorphic disorder. Indian J Psychiatry 61(Suppl 1), 131-135. http://dx.doi.org/10.4103/psychiatry.IndianJPsychiatry 528_18

28. Uzun O, Basoglu C, Akar A, Cansever A, Ozşahin A et al. (2003) Body dysmorphic disorder in patients with acne. Compr Psychiatry 44(5), 415-419. http://dx.doi.org/10.1016/S0010440X(03)00102-0

29. Vargel S and Ulusahin A (2001) Psychopathology and body image in cosmetic surgery patients. Aesthetic Plast Surg 25, 474-478. http://dx.doi.org/10.1007/s00266-001-0009-7

30. Veale D, Ellison N, Werner TG, Dodhia R, Serfaty MA et al. (2012) Development of a Cosmetic Procedure Screening Questionnaire (COPS) for Body Dysmorphic Disorder. Journal of Plastic, Reconstructive \& Aesthetic Surgery 65(4), 530-532. http://dx.doi. org/10.1016/j.bjps.2011.09.007.

31. Veale D, Gledhill LJ, Christodoulou P, Hodsoll J (2016) Body dysmorphic disorder in different settings: A systematic review and estimated weighted prevalence. Body Image 18, 168-186. http://dx.doi.org/10.1016/j.bodyim.2016.07.003

32. Vulink NC, Sigurdsson V, Kon M, Bruijnzeel-Koomen CA, Westenberg HG et al. (2006) Body dysmorphic disorder in 3-8\% of patients in outpatient dermatology and plastic surgery clinics. Ned Tijdschr Geneeskd 150(2), 97-100.

33. Wang Q, Cao C, Guo R, Li X, Lu L et al. (2016) Avoiding Psychological Pitfalls in Aesthetic Medical Procedures. Aesthetic Plast Surg 40(6), 954-961. http://dx.doi.org/10.1007/s00266016-0715-9 